\title{
Actions that contribute to a better quality of life of women
}

\begin{abstract}
The objective of this article of opinion is to describe some actions that contribute to a better quality of life of women, since many of them do not perform physical activity, do not participate in community therapies to expose their anguish and problems of the day, and do not dedicate themselves the elaboration of handicrafts and differentiated food dishes that can contribute to a better quality of life. As consequence, several depressive conditions and symptoms have affected such individuals, which generates higher costs to the public coffers and the weakening of family and interpersonal relationships.
\end{abstract}

Keywords: physical activity, group therapy, handicraft, cooking workshops
Volume 8 Issue I - 2018

\author{
Martha Elisa Ferreira de Almeida \\ Institute of Biological Sciences and Health, Federal University of \\ Viçosa, Brazil

\begin{abstract}
Correspondence: Martha Elisa Ferreira de Almeida, Institute of Biological Sciences and Health, Federal University of Viçosa (UFV/CRP), Rio Paranaíba Campus, Post Office: 22, Rio Paranaíba, MG, Brazil, Zip Code: 388I0-000; Tel +553438558I39, Email martha.almeida@ufv.br
\end{abstract}

Received: December 22, 2017 | Published: January 18, 2018

\section{Opinion}

According to the World Health Organization (WHO), health is "the complete well-being and full development of physical, psychoemotional and social potentialities and not the mere absence of disease or infirmity." In this way, the human being is healthy when it presents a productive and harmonic relationship with the environment, and its culture. ${ }^{1}$ Various effects on the well-being of individuals are attributed to the multiple functions they perform. Currently there has been an increase in depressive symptoms in women who assume only the domestic function, since the routine of household tasks, the lack of recognition of these activities, and the responsibility for the family's well-being are factors that can lead to social isolation and, consequently, emotional exhaustion. ${ }^{2}$ This problem affects the populations of developed and developing countries, being a reflection of the great changes that have been taking place in the lifestyle of the people in the world, especially regarding the eating habits and the practice of physical activity. ${ }^{1}$

The daily practice of physical activity is important both in the prevention and treatment of various diseases and helps in socialization. However, for many women such action becomes a barrier to the innumerable daily activities performed in the home environment and also with family care. Individuals who practice physical activity present a better quality of life as the aspects of physical, psychological and cognitive health. ${ }^{3}$

Several group therapy programs have improved the quality of life of the human being. Overweight and obese adults who participated in the Weight Watchers Program were twice as heavy as those who only received medical advice over 12 months because such individuals were motivated and changed their lifestyles. ${ }^{4}$ Group therapy facilitates the verbalization of feelings and hidden emotions so that you do not get sick because speech ends up being a powerful medicine and excellent therapy. And when you can verbalize what you are feeling and share the pain, there is a decrease in the tensions generated by the losses and the anguish. ${ }^{5}$ In the group process, when people realize that they are not the only ones experiencing a problem, this is seen as a source of relief. ${ }^{6}$ By living in a group with people with similar demands, a climate of great therapeutic value can develop, as it will help participants break down barriers created by feelings of loneliness and isolation, as they can receive constructive suggestions from others who have experienced the same problems. ${ }^{7}$

The handicraft groups have promoted to the participants a wellbeing and a great learning to solve day-to-day problems, as well as to promote the reciprocal help in which each individual will take care of the self, of the other, and of the community where if one lives, ${ }^{8}$ besides offering favorable conditions for psychosocial development that will reflect on mental health. ${ }^{9}$ The importance of craftsmanship in quality of life was highlighted for the first time in the 1970s by the important role played in the lives of men and societies..$^{10}$ Reading, writing, and crafts such as crafts and painting are the best way to exercise the brain to preserve memory. People who performed simple tasks such as sewing, knitting, woodworking, and gluing were seven times less likely to have dementia than those who did no activity. Drawing, painting and craftsmanship serve as a therapeutic resource, as it has direct action on the nerve endings, which are located at the fingertips that are attached to the various parts of the brain, increasing perception, attention and language. Another important factor attributed to craftsmanship is the social interaction that it provides when it is practiced in a group. ${ }^{11}$ It was identified that the women who made handicrafts presented a change of their routine, with moments of pleasure and a rupture with the tension of the daily problems. They experience moments of creativity, occupation of spaces and times, are distracted, and laugh and take care of themselves. ${ }^{9}$

Much has been heard about healthy eating as a means of preventing chronic non-communicable diseases. However, many housewives still feel unmotivated and creative about food preparation, and group cooking workshops can positively contribute to the exchange of information on combining various foods. The creativity in the kitchen represents for many a risk or an adventure to be lived, as an opportunity to break the prejudices of the culinary practice. The creative process may occur in the preparation techniques used, in the harmony of flavors created or in the presentation and final decoration of the dishes. For a creative person, what seems to be a limitation may be the starting point for new ideas with creative solutions to adversity. ${ }^{12}$ Quality of life is an important factor, and is based on the environment, cultural identity and well-being that include the interrelationships 
between work-education, education-health and employment-health Quality of life reflects the degree of satisfaction found in family, love, social and environmental life and to the aesthetics itself. ${ }^{13}$

It is concluded that physical activity and group therapies to solve health problems, as well as the development of handicrafts and healthier meals, have contributed significantly to improve nutritional conditions and other aspects that contribute to the quality of life of individuals, especially women who are exclusively engaged in domestic and family activities, and who may develop various chronic non-communicable diseases.

\section{Acknowledgements}

None.

\section{Conflict of interest}

The author declares no conflict of interset.

\section{References}

1. Ministry of Health Brazil. Food guide for the Brazilian population. 2nd ed. Brazil: Ministry of Health, Department of Health Care, Department of Basic Attention; 2014.

2. Andrade LHSG, Viana MC, Silveira CM. Epidemiology of psychiatric disorders in women. Rev Psiquiatr Clin. 2006;33(2):43-54.

3. Silva RS, Silva I, Silva RA, et al. Physical activity and quality of life Ciênc Saúde Colet. 2010;15(1):115-120.

4. Jebb SA, Ahern AL, Olson AD, et al. Primary care referral to a commercial provider for weight loss versus standard care: a randomized controlled trial. Lancet. 2011;378(9801):1485-1492.
5. Malheiros E. The use of speech as an instrument for restoring psychosomatic ills and improving the quality of life. In: Grandesso M, Barreto MR, editors. Community therapy: health, education and public policy. São Paulo: House of the Psychologist Brazil; 2007.

6. Yalom ID, Leszcz M. Group psychotherapy: Theory and Practice. Brazil: Artmed; 2006.

7. Costa KS, Munari DB. Weight control group in the process of health education. R Enferm UERJ. 2004;12(1):54-59.

8. Tahan-Santos E, Cardoso CL. Experiences of participants in a Health Promotion Group in the Family Health Strategy. Psico. 2008;39(4):410 417.

9. Scardoelli MG, Waidman MAP. Artisan group: a favourable space promoting mental health. Esc Anna Nery. 2011;15(2):291-299.

10. Gonçalves RC. Lives in the labyrinth: women and artisanal work - a study on the artisans of the Chã dos Pereira - Ingá, PB. Brazil: Master's Dissertation in Sociology, Human Sciences, Letters and Arts Center, Federal University of Paraíba; 1996.

11. Crafts: Did you know that craftsmanship helps to improve the quality of life of the Senior Generation?

12. Ferreira A. Creativity and Gastronomy: an Exploratory Study. Dissertation Master in Computer Science. Portugal: University Institute: Psychological, Social and Life Sciences; 2012.

13. Alguacil J. Quality of Life and urban praxis: new initiatives of citizen management in the social periphery of Madrid. Spain: $21^{\text {st }}$ Century of Spain Publishers; 2000. 